\title{
CONTRIBUIÇÃO DA FILOSOFIA DA MICROBIOLOGIA PARA FUNDAMENTAR A ZONA RELACIONAL DO PERFIL CONCEITUAL DE VIDA
}

\author{
Francisco Ângelo Coutinho* \\ Rogério Parentoni Martins** \\ Marcos Costa Vieira***

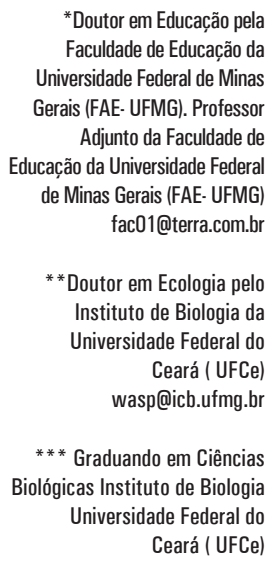

RESUMO: Discute-se, neste estudo, como as reflexões da filosofia da Microbiologia podem contribuir para fundamentar a zona relacional do conceito biológico vida e os benefícios que traria para o aprendizado dos alunos em virtude de sua utilização em sala de aula. A partir da definição do conceito vida como adaptação flexível, argumenta-se sobre a possibilidade de que o ensino em Biologia seja sintético ao invés de meramente analítico. Para alcançar esse objetivo, fundamenta-se na zona relacional do conceito vida e se discute de que formas as consequências dessa fundamentação podem contribuir para a prática do ensino em Biologia. Simultaneamente, espera-se contribuir para reforçar o programa de pesquisas sobre perfis conceituais, uma vez que isso trará consequências positivas para a compreensão dos aspectos ontológicos e epistemológicos das zonas do perfil de um conceito científico. Palavras-chave: Conceito vida; Perfil Conceitual; Ensino de Biologia; Filosofia da Biologia.

CONTRIBUTION OF PHILOSOPHY OF MICROBIOLOGY IN SUPPORT OF THE RELATIONAL ZONE OF THE CONCEPTUAL PROFILE OF LIFE

ABSTRACT: We discuss how reflections on the philosophy of microbiology may contribute to set up the foundations of a relational zone for the biological concept of life and how it would improve student learning if used inclassroom. Starting from the definition of life as flexible adaptation, we argue that a synthetic treatment of biology teaching should replace the current analytical approach. For that purpose, we lay out the fundamentals of the relational zone for a concept of life and discuss how the consequences arising from the definition of such fundamentals may contribute to the practice of biology teaching. At the same time, we hope that our contribution will strengthen the research program on conceptual profiles, for this shall bring positive consequences to the comprehension of the ontological and epistemological aspects of the profile zones of a scientific concept.

Keywords: concept of life, conceptual profile, Biology teaching, Philosophy of Biology 


\section{INTRODUÇÃO}

A constituição de uma filosofia da Microbiologia iniciou-se em 2006 a partir de um workshop, Philosophical and Social Dimensions of Microbiology, realizado na Universidade de Exeter, Inglaterra (O’MALLEY e DUPRÉ, 2007a). Naquela ocasião, filósofos, historiadores da Biologia, sociólogos da ciência e biólogos apresentaram trabalhos, publicados em Studies in History and Philosophy of Biological and Biomedical Sciences (vol. 38, n.4, 2007). Nestes trabalhos, há contribuições que auxiliam a compreender o significado do conceito vida.

A motivação deste artigo se deu a partir da reflexão de que embora o conceito vida seja fundamental no ensino em Biologia, muitas vezes ele não é facilmente apreendido devido à sua complexidade. Partiu-se da ideia de que a constituição de um campo científico está intimamente ligada à sua autolimitação em virtude da necessária construção de afirmações sobre fenômenos e objetos de estudos que são abordados cientificamente (VIDEIRA, 2000). Deste modo, uma das mais importantes etapas do fazer científico é a elaboração de teorias - estruturas linguísticas que interpretam aquilo que percebemos ou acreditamos existir no mundo dos fenômenos (VIDEIRA, 2000). No entanto, tais teorias contêm, em sua estrutura, conceitos que nem sempre correspondem a objetos do mundo, pois um conceito científico não deve ser entendido como substituto do objeto natural ao qual se intenta dar significado. Nessa perspectiva, conceitos científicos são mais do que apenas uma replicação da estrutura e funcionamento do mundo, na medida em que seus significados são estabelecidos por meio de suas inserções em redes linguísticas de práticas teóricas, experimentais e comunicativas complexas (EMMECHE e EL-HANI, 2000).

Portanto, em cada ramo do conhecimento científico sobre o mundo há conceitos de significado abrangente, cujas funções são as de facilitar a unificação teórica de determinado ramo científico, a exemplo do conceito vida em Biologia (Emmeche e El-Hani, 2000). Tais conceitos, denominados ontodefinições (EMMECHE e EL-HANI, 2000), cumprem papel integrador na estruturação do paradigma científico do qual fazem parte. No presente estudo, salientamos que em Biologia definir vida advém da necessidade de se dispor, da melhor forma possível, um contorno nítido sobre o objeto de estudo que essa disciplina aborda. Essa nitidez pode ser obtida por meio da organização coerente e unificada dos modelos, teorias, metáforas e entidades que, apesar de integrarem o mundo representacional da Biologia, são indispensáveis ao entendimento científico desse ramo da ciência, o que facilita a comunicação entre os estudiosos. Além disso, a Biologia necessita de uma profunda transformação que é justamente a integração de campos conceituais antes isolados em disciplinas bem estruturadas cujos territórios estejam bem definidos (KAFATOS e EISNER, 2004). Para que essa unificação ocorra, é necessário explicitar os conceitos unificadores. Finalmente, tal organização unificada e coerente é necessária para que a Biologia seja considerada ciência autônoma, isto é, para que seu objeto de estudo seja discernível daquele de outras ciências, tais quais a Física e a Química (Cf. EMMECHE e EL-HANI, 2000). No que diz respeito ao 
ensino em Biologia, em vez de se utilizar um currículo que enfatize o saber enciclopédico, bem melhor seria reconhecer os temas unificadores capazes de integrar os campos dessa ciência (EMMECHE e El-HANI, 2000). Segundo estes autores, a ideia básica seria relacionar os tantos e diversos conceitos da Biologia a alguns poucos conceitos unificadores, mais gerais, de modo a propiciar condições para que os alunos construam um conhecimento biológico sintético e, portanto, abrangente, em oposição a um conhecimento meramente analítico. Assim, esses poucos conceitos unificadores seriam os "atratores" dos mencionados diversos conceitos que organizariam e, sobretudo, sintetizariam seus múltiplos significados.

Essa concepção encontra respaldo em vários autores quando afirmam que aprendizagem significativa ocorre por meio de sínteses, utilizando-se alguns conceitos facilitadores. Por exemplo, um importante passo em direção à aprendizagem significativa é o da diferenciação progressiva, ou seja, o processo pelo qual os conceitos mais abrangentes são, sucessivamente, decompostos em conceitos mais específicos (AUSUBEL et al. 1980). Porém, a par desse processo, deve ocorrer o oposto, a reconciliação integradora, ou seja, a partir dos conceitos mais específicos integra-se sucessivamente até serem obtidos conceitos abrangentes. Sob essa perspectiva, o processo de ensino/aprendizagem partiria de conceitos potencialmente significativos, mais abstratos, gerais e inclusivos, que subsumiriam ou subordinariam os conceitos mais específicos.

No caso do ensino em Biologia, a preocupação em definir vida da forma mais abrangente possível se torna relevante na medida em que esse conceito integrador constitui um operador e facilitador da aprendizagem. Assim, o pressuposto-base seria o de que processo de ensino em Biologia fosse mais sintético e menos analítico, a fim de que o aluno obtenha uma melhor compreensão científica. O inverso e indesejável seria que ele mantivesse memorizado apenas um elenco de conceitos, repetidos em momentos oportunos. Isso nos conduz à ideia de que propor definições adequadas dos conceitos em disciplinas de seus interesses é tarefa importante que cientistas, filósofos da ciência e educadores devem desempenhar (MAHNER, 1998). Para que definições adequadas dos conceitos possam ser propostas, deve-se selecionar aqueles conceitos que seriam os facilitadores para que uma construção sintética do conhecimento possa ocorrer. Todavia, para que tal objetivo seja alcançável, a noção de "definições adequadas dos conceitos" deve ser esclarecida por meio da explicitação de critérios específicos.

A definição do conceito vida deveria satisfazer os critérios de coerência em relação ao estado atual do conhecimento científico, consistência, elegância, poder explicativo e universalidade (ZHURAVLEV e AVETISOV, 2006). No entanto, uma definição é sempre elaborada a partir de compromissos ontológicos e epistemológicos necessariamente assumidos; por isso, ao se utilizar o modelo de perfil conceitual, é possível evidenciar o modo pelo qual definições adequadas se conectam às zonas do perfil do conceito. Nessa perspectiva, e à procura de um ensino comprometido com a síntese mais do que análise, além de enfatizar suas consequências para o desenvolvimento de pesquisas em Biologia, apresentaremos 
as articulações que a filosofia da Microbiologia estabelece com a concepção relacional do perfil conceitual vida.

Alerta-se não se pretender aqui propor uma nova definição de vida, que seria apenas uma a mais a integrar um extenso elenco de definições. Ao contrário, utiliza-se a definição encontrada em Bedau (1996 e 1998) que, no entanto, não é o único a se basear na concepção relacional de vida (veja COUTINHO, 2005). Contudo, outras fontes e referências sobre perfis conceituais da Biologia também serão abordadas, tendo em vista fundamentos ontológicos e epistemológicos do conceito vida.

\section{PERFIL CONCEITUAL E AS ZONAS DO CONCEITO VIDA}

Uma das maiores conquistas não positivista obtida pela epistemologia no século XX foi constatar que diferentes cientistas, em um mesmo campo do conhecimento, organizam e interpretam aspectos da natureza de modos distintos (e.g., HANSON, 1958; KUHN, 1970 e FEYERABEND, 1975). A adoção de sistemas conceituais diferentes implica na redefinição do campo de trabalho. Ou seja, diferentes conceitualizações permitem diferentes observações, inferências, explicações, modelos e metáforas (KITCHER, 1993).

Ideia similar é a de que há diferentes modos de expressar conceitos sobre a realidade (BACHELARD, 1978). Ele quem? Bachelard? demonstrou a insuficiência de uma única doutrina filosófica para descrever todas as diferentes formas de se pensar quando se pretende expor e explicar um único conceito científico. Argumentou ainda que apenas a consideração de um único conceito evidencia a incompletude de várias filosofias porque estas, ao se apoiarem em um único aspecto, esclarecem apenas uma das múltiplas facetas do conceito. Dessa forma, Bachelard propõe a noção de perfil epistemológico: "uma escala graduada de discussão que nos permite localizar os diferentes pontos na filosofia científica e evitar a confusão de argumentos" (BACHELARD, 1978, p. 34).

A partir da proposição dessa noção e de acordo com várias tradições epistemológicas atuais, Mortimer $(1995,2000)$ propôs o modelo perfil conceitual. Esse modelo assume que indivíduos diferentes podem ter maneiras distintas de observar e representar o mundo, as quais são usadas em contextos diferenciados. Estabelece ainda o modelo a distinção entre as características ontológicas e epistemológicas de cada zona que constitui o perfil de determinado conceito. Em um mesmo conceito, cada zona de seu perfil pode ser epistemológica e ontologicamente diferente das demais, posto que essas duas características podem mudar à medida que se mova através do perfil. A consequência prática da aplicação do modelo de perfil conceitual é a de que é possível identificar diferentes modos de pensar em contextos diversos.

Assim, estamos em condições de expressar o que se entende por "definições adequadas dos conceitos". Admitimos que estas só podem ocorrer quando os compromissos ontológicos e epistemológicos do conceito forem explicitados. 
Para que isso aconteça, é necessário estabelecer quais seriam as diversas zonas que integram o perfil de certo conceito. Consequentemente, não há uma única definição possível para determinado conceito científico, mas quaisquer definições serão proferidas sob a perspectiva de certa zona do perfil.

Dos pontos de vista epistemológico e ontológico, o conceito vida é constituído por três zonas, cada uma delas representando um nível distinto de compreensão (COUTINHO, 2005; COUTINHO et al., 2007). A "internalista" é aquela referente às concepções de vida como processos, propriedades ou objetos inerentes ao vivente. Nesse caso, noções que propõem vida caracterizada apenas pela estrutura e funções moleculares que constituem o vivente se acomodariam nessa zona. Salienta-se a importância que essa zona desempenha na construção de significados em genética, bioquímica e biologia molecular, por exemplo por meio delas, essa zona é reforçada e ampliada no decorrer do processo de ensino. A zona "externalista" é a que entende vida como algo que se manifestaria externamente à própria constituição do vivente, isto é, vida seria algo que se manifestaria por meio de uma influência externa ou que tenderia a uma finalidade além do simples viver. Essa zona do perfil abrangeria concepções religiosas e filosóficas, tais como o cristianismo e o neoplatonismo. No entanto, embora amplamente difundida nos contextos socioculturais humanos, essa zona é ignorada no discurso científico atual. A terceira e última, "relacional", é a que inclui a concepção vida como relação entre entidades e/ou sistemas. Nessa zona, situa-se a compreensão de que vida não é uma propriedade dos organismos em si, isoladamente, mas resulta das interações estabelecidas pelos organismos entre si e o meio físico-químico. Além disso, como resultado dessas interações há a produção de um meio específico e adequado à manutenção da própria interação.

Como dissemos, considerar a zona internalista do perfil conceitual vida é importante para se compreender os sistemas vivos em termos de suas propriedades (nascer, morrer, reproduzir, metabolizar, possuir determinada estrutura e organização molecular, etc.). Disciplinas tais como a Genética e a Bioquímica necessitam que o aluno acesse essa zona e tenha consciência que ela exista. Ato contínuo, o contato com essas disciplinas reforçará e expandirá essa zona do perfil. Porém, disciplinas como Ecologia e Evolução necessitam, em maior proporção, de que vida seja compreendida em termos de relações. Conceitos tais como adaptação, seleção, comunidade, biodiversidade, nicho e ciclos geoquímicos, por exemplo, só podem ser adequadamente definidos sob a perspectiva de que as entidades em foco estão inter-relacionadas. Da mesma forma que acontece à zona internalista, a relacional se reforça e expande por meio do contato estabelecido com as disciplinas ecologia e evolução.

A zona relacional do conceito de vida, no entanto, não é uma concepção cotidiana do que normalmente pensamos sobre vida; por isso, ao se buscar uma compreensão do que vida significa, deve-se ter em mente que nossa concepção cotidiana pode nada ter a ver com uma definição científica adequada do conceito de vida (BEDAU, 1996). Tal como exposto acima, relembramos que uma definição 
adequada deve satisfazer os aspectos ontológicos e epistemológicos de uma determinada zona do perfil do conceito. Bedau (1996), por exemplo, ao afirmar que vida é um tipo natural (natural kind), propõe uma definição radical que tem sua base na evolução: vida é "adaptação flexível" (supple adaptation). Normalmente as definições de vida estão focalizadas em algum tipo de individualidade distinguível das demais (seja ela a célula, o organismo, o gene ou até mesmo o planeta Terra, tal qual proposto na formulação da Hipótese Gaia). No entanto, sistemas vivos exploram continuamente seus nichos e trocam materiais, energia e informação com seus ambientes. Assim, Bedau, em vez de focar na individualidade afirma que um sistema capaz de adaptar-se às contingências de um ambiente imprevisível (adaptação flexível) deveria ser considerado como a forma de vida primária. Um sistema exibe adaptação flexível quando produz e obtém respostas significativas originais resultantes de novos tipos de desafios e oportunidades adaptativas (BEDAU, 1998). Um sistema que exibe adaptação flexível pode ser uma população ou ecossistema, entendidos em suas múltiplas interações (BEDAU, 1998).

Ainda segundo Bedau, componentes particulares em um sistema que exibe adaptação flexível, como por exemplo um único organismo, são incapazes de evoluir - pois essa é uma propriedade de populações - e, por não o serem, não poderão ser entendidos como vivos. O componente particular deve ser qualificado como vivo forma secundária de vida - somente em virtude de suas relações dentro do sistema que exibe um processo evolutivo de contínua adaptação às mudanças ambientais e, nesse processo, modifica esse ambiente em função de suas necessidades e vínculos com outros seres vivos. A mula, por exemplo, é qualificada como ser vivo em função de participar de uma população reprodutiva, mas, pelo fato de ser estéril, deve ser entendida como forma secundária de vida (BEDAU, 1998).

A definição de vida como adaptação flexível se situa na zona relacional do conceito vida, e assumimos que seja uma definição adequada. Vida, por meio dessa abordagem, deve ser compreendida como relação, porque sistemas que exibem adaptação flexível o fazem por meio de relações que entidades estabelecem entre si e com o meio em que vivem. Se assim o for, vida se manifesta em diferentes níveis de organização e, por isso, distinguir entre vivente e não vivente torna-se uma questão de escala, e não de ser tudo ou nada.

Sob essa concepção, pode parecer supérfluo que se busque contribuir para fundamentar a zona relacional do perfil conceitual vida. Pode-se argumentar que a constatação de sua existência se baseou em evidências suficientes, o que a fundamentaria adequadamente. Essa, porém, é só uma parte da história. É bem verdade que as zonas do perfil conceitual de vida foram compostas segundo uma metodologia que articula os domínios genéticos do conceito: sociocultural, ontogenético e microgenético (Werstsch, 1985; para detalhes, veja também Coutinho, 2005 e Coutinho et al., 2007). No entanto, nos preocupamos, aqui, com o valor heurístico que a zona relacional possa ter no decorrer do processo educacional e, para tanto, é necessário explicitar suas condições de uso. Essa preocupação é coerente, por exemplo, com as Orientações Curriculares Nacionais, que estabelecem 
a necessidade de que o aluno seja capaz de reconhecer que os sistemas vivos mantêm intrincadas relações entre si e com o ambiente (BRASIL, 2006).

Em acordo com essa determinação que julgamos importante para uma realização efetiva do aprendizado, tentaremos mostrar que a microbiologia deve ser valorizada devido à sua contribuição importante não apenas para o desenvolvimento da filosofia da Biologia e das pesquisas educacionais que nela se sustentam, mas também para que o ensino de Biologia seja epistemologicamente fundamentado.

\section{ALGUMAS CONSTATAC̣ÕES DA FILOSOFIA DA MICROBIOLOGIA}

Um importante ponto de partida diz respeito ao aumento significativo de evidências de que considerar os micro-organismos exclusivamente unicelulares seja uma concepção equivocada. Isso porque essa concepção se baseia em modelos formulados a partir de estudos em laboratório que abordam o crescimento de colônias monoespecíficas (O’MALLEY e DUPRÉ, 2007ª; DAVE e O’TOOLE, 2000). Ao contrário, poucas vezes os micro-organismos vivem isoladamente. A regra é a de que existam por meio de uma grande variedade de associações que estabelecem com outros organismos, especialmente metazoários. Tais relações se dão por meio de competição, parasitismo, comensalismo e mutualismo (O’MALLEY e DUPRÉ, 2007a).

A definição normalmente aceita para multicelularidade enfatiza a existência de divisão de tarefas realizadas por meio de tecidos diferenciados e a alteração permanente da expressão gênica. No entanto, comunidades de micro-organismos exibem organização celular bem definida que inclui interações especializadas entre células, supressão da autonomia celular e da competição. Ainda, tais comunidades comportam-se cooperativamente, abrangendo inclusive a reprodução, a exemplo dos conhecidos biofilmes. Desse modo, micro-organismos trabalham juntos, caracterizando uma unidade funcional (O'MALLEY e DUPRÉ, 2007a).

Entre as categorias tradicionais da filosofia da Biologia, encontramos a de organismo individual e sua linhagem (O’MALLEY e DUPRÉ, 2007a). Nessa visão filosófica tradicional, populações são entendidas como sendo constituídas por meio de agregados de indivíduos. No entanto, a existência dos biofilmes traz um empecilho importante para que essa visão possa ser aceita. O motivo é o fato de que os biofilmes operam como unidades funcionais e são mais do que simples agregados de indivíduos. Biofilmes são modos de vida adotados em todos os ambientes por muitas espécies de procariotos. Estes são definidos como conjuntos de micro-organismos e seus produtos extracelulares associados e tipicamente ligados a uma superfície abiótica ou biótica (DAVE e O’TOOLE, 2000). Podem ser constituídos de apenas uma única ou várias espécies microbianas (O’TOOLE et al., 2000). A construção de um biofilme envolve vários estágios: adesão em uma única camada, formação de múltiplas camadas e maturação. Os micro-organismos sofrem profundas mudanças durante sua transição da forma livre para as células que fazem 
parte do complexo organismo chamado biofilme. Essas mudanças são novas características fenotípicas desenvolvidas pelos micro-organismos (O’TOOLE et al., 2000). Além disso, a expressão gênica muda em cada um dos estágios de desenvolvimento (O’MALLEY e DUPRÉ, 2007a). Muitos desses biofilmes exibem, ainda, complexa diferenciação celular e comportamento coletivo (DAVE e O’TOOLE, 2000). Esse exemplo mostra a importância de se expandir essa zona relacional do perfil conceitual vida para que esse fenômeno seja adequadamente compreendido, especialmente porque, conforme a definição de vida de Bedau, o conceito se aplica a diferentes níveis de organização. Esse exemplo é um desses casos, pois as relações em um biofilme são tão íntimas que sua formação deveria ser considerada um processo de desenvolvimento multicelular (O'TOOLE, 2000).

Outro fenômeno importante para substanciar nossa argumentação diz respeito à transferência lateral e horizontal de genes. Essa é a transferência de material genético de um organismo para outro, mais comumente por conjugação, transdução ou transformação (O’MALLEY e DUPRÉ, 2007b). A transferência de material genético resulta em variabilidade que permite uma rápida adaptação das comunidades a mudanças ambientais (REANNEY et al. 1982). Por meio dessa transferência e suas consequências surgem novas capacidades para interagir com o ambiente cambiante, novas funções metabólicas, resistência a antibióticos e aumento da patogenia. Avanços recentes nos estudos sobre genômica microbiana sugerem que vários domínios de proteínas são comuns a bactérias e eucariotos. Em particular, procariontes parecem compartilhar várias vias de sinalização com eucariotos. A transferência lateral de genes codificantes de domínios de proteína, originalmente de origem bacteriana, parece ter contribuído para a evolução das vias sensoriais relacionadas com luz, sinalização redox, vias de desenvolvimento e de sinalização de citocinas e citocininas em eucariotos (ARAVIND et al., 2003). Estudos filogenéticos moleculares revelam que endossimbiose entre bactérias e invertebrados é resultado de infecções antigas seguidas por transmissão vertical que ocorreu na linhagem do "hospedeiro". Tais estudos revelaram a existência de atributos benéficos, tal como a amplificação de genes subjacentes ao fornecimento de nutrientes (MORAN e BAUMANN, 2000). A transferência lateral também parece ter atuado no único caso conhecido de um animal capaz de realizar a síntese de compostos carotenóides: os ancestrais do afídeo Acyrthosiphon pisum parecem ter herdado tal capacidade em decorrência de genes transferidos a partir de um fungo ancestral, talvez um parasita ou um endossimbionte (MORAN e JARVIK, 2010). De fato, a própria incorporação de micro-organismos ancestrais e sua evolução nas modernas organelas (de acordo com a teoria endossimbiótica; veja abaixo) parece ter sido acompanhada de uma transferência maciça de material genético do genoma organelar para o genoma nuclear - um processo que se estende desde mais de um bilhão de anos até o presente, e que moldou e continua a moldar o próprio genoma eucariótico moderno (TIMMIS et al., 2004).

Os exemplos de transferência lateral e horizontal de genes ilustram não apenas como são íntimas as relações entre os seres vivos, mas também levantam 
importantes questões ontológicas e epistemológicas. Em primeiro lugar, questões relativas a fronteiras. Tradicionalmente, uma opinião geral dentro da filosofia da Biologia é a de que o organismo é a categoria ontológica central. No entanto, transferências lateral e horizontal de genes estabelecem problemas sérios para a ideia da existência de fronteiras intra e interespecífica nítidas (O’MALLEY e DUPRÉ, 2007b). Em segundo lugar, tais exemplos evidenciam a questão epistemológica sobre como devemos compreender a individualidade biológica, o conceito de herança e transmissão de informação e o processo evolutivo, bem como o conceito de espécie (O’MALLEY e DUPRÉ, 2007b).

Para finalizar nossos exemplos, vejamos a teoria endossimbiótica desenvolvida por Lynn Margulis, nos anos 1960, e publicada em 1967 (com o nome Sagan). Margulis pretendeu resolver um dos maiores problemas da biologia evolutiva: a origem da célula eucariota. Partindo do fato de que existem curiosas similaridades entre células procariotas e algumas organelas de células eucariotas (Quadro1), Margulis recuperou a teoria proposta, em 1910 pelo biólogo russo Mereschowsky e em 1920 pelo norte-americano Ivan Wallin, sobre quem seriam os possíveis ancestrais das mitocôndrias e dos cloroplastos (FENCHEL, 2002).

Quadro: Similaridades e diferenças entre células procariotas, células eucariotas, mitocôndrias e cloroplastos.

\begin{tabular}{|c|c|c|c|c|}
\hline & Procariotas & Eucariotas & Mitocôndria & Cloroplasto \\
\hline DNA & $\begin{array}{l}1 \text { cromossomo } \\
\text { circular }\end{array}$ & $\begin{array}{l}\text { Múltiplos } \\
\text { cromossomos } \\
\text { lineares com- } \\
\text { partimentali- } \\
\text { zados dentro } \\
\text { do núcleo }\end{array}$ & $\begin{array}{l}1 \text { cromossomo } \\
\text { circular }\end{array}$ & $\begin{array}{l}1 \text { cromossomo } \\
\text { circular }\end{array}$ \\
\hline Ribossomo & $70 \mathrm{~S}$ & $80 \mathrm{~S}$ & $70 \mathrm{~S}$ & $70 \mathrm{~S}$ \\
\hline $\begin{array}{l}\text { Cadeia } \\
\text { transportadora } \\
\text { de elétrons }\end{array}$ & $\begin{array}{l}\text { Encontrada } \\
\text { na membrana } \\
\text { plasmática em } \\
\text { torno da célula }\end{array}$ & $\begin{array}{l}\text { Não encontrada } \\
\text { na membrana } \\
\text { plasmática } \\
\text { em torno } \\
\text { da célula } \\
\text { (encontrada } \\
\text { somente na } \\
\text { mitocôndria e } \\
\text { no cloroplasto) }\end{array}$ & $\begin{array}{l}\text { Encontrada } \\
\text { na membrana } \\
\text { em torno da } \\
\text { mitocôndria }\end{array}$ & $\begin{array}{l}\text { Encontrada } \\
\text { na membrana } \\
\text { plasmática } \\
\text { em torno do } \\
\text { cloroplasto }\end{array}$ \\
\hline $\begin{array}{l}\text { Tamanho } \\
\text { (aproximado] }\end{array}$ & 〜-10 mícrons & $\begin{array}{l}\text { 50 - } 500 \\
\text { mícrons }\end{array}$ & 〜-10 mícrons & 1-10 mícrons \\
\hline
\end{tabular}

Fonte: modificado a partir de http://www.biology.iupui.edu/biocourses/N100/2k2endosymb.html. Acesso em 30/03/2010

A teoria da endossimbiose propõe que as mitocôndrias se originaram da endocitose efetuada por um ancestral das células eucariotas de bactérias aeróbicas e os cloroplastos da endocitose de bactérias fotossintetizantes. Essa relação se tornou mutuamente benéfica para as células. A simbiose se deu a partir do momento 
em que a atmosfera começou a apresentar uma concentração substancial de oxigênio e que organismos aeróbios com maior capacidade de produzir energia surgiram na Terra. Segundo a hipótese de Margulis-Sagan, a bactéria aeróbica teria manipulado o oxigênio tóxico para a bactéria anaeróbica e a bactéria anaeróbica ingeriria comida para a bactéria aeróbica.

A teoria endossimbiótica apresenta muito mais detalhes e evidências do que seria recomendável expor aqui, já que o que nos interessa são as consequências dessa teoria para uma compreensão do conceito vida. O importante, segundo Margulis-Sagan, é que a teoria endossimbiótica se refere não apenas à origem de novos organismos, mas também de novas espécies por meio da simbiose permanente ou de longo prazo (MARGULIS, 2001). Nessa concepção, a simbiose foi decisiva para o entendimento da inovação evolutiva e da origem das espécies. Resta-nos extrair uma possível concepção sobre o que é vida a partir da teoria endossimbiótica.

Um exemplo significativo é o da análise que Margulis realizou sobre o “kefir”. A palavra 'kefir' se refere tanto à bebida láctea como ao coalho e os grânulos que fermentam o leite. Assim como os ancestrais de todos os eucariotas evoluíram a partir de simbioses entre bactérias, indivíduos de kefir evoluíram a partir da união de cerca de trinta micro-organismos diferentes, pertencentes aos reinos Monera e Fungi (MARGULIS, 2002). Essas bactérias e leveduras precisam reproduzir-se em conjunto - por intermédio de divisão celular coordenada e sem a ocorrência da fertilização ou de qualquer outro aspecto de sexo meiótico - para manter a integridade do indivíduo que é o coalho do kefir (MARGULIS, 2002). Ao longo das gerações, ao selecionarem as melhores "sementes" para a fabricação da bebida láctea, os habitantes do Cáucaso criaram uma nova forma de vida. Os micro-organismos que compõem o "kefir" estão completamente integrados em um novo ser. Assim como o "kefir", nós e os demais organismos, de amebas a baleias, feitos de células nucleadas, não somos apenas indivíduos, mas agregados simbiônticos de outros indivíduos (MARGULIS, 2002).

Esses são, portanto, bons exemplos por meio dos quais é possível operacionalizar uma concepção relacional de vida em sala de aula. Ao mesmo tempo, a compreensão desses fenômenos exige a explicitação dessa zona do perfil conceitual. Numerosos exemplos adicionais poderiam ser apresentados, no entanto, os que foram discutidos são suficientes para que deles sejam extraídas consequências que podem influenciar o ensino em Biologia.

\section{CONSEQUÊNCIAS PARA O ENSINO EM BIOLOGIA}

Os exemplos aqui discutidos expõem questões ontológicas e epistemológicas cujas respostas são importantes para que a compreensão da Biologia e seu tratamento em sala de aula sejam mais próximos do conhecimento científico atual. Em primeiro lugar, o conceito vida, ontologicamente, aponta para níveis hierárquicos múltiplos. Vida não é uma substância ou uma entidade, mas um conceito que diz 
respeito a processos ocorrentes de células a ecossistemas. Expõem também o problema epistemológico de que o conhecimento em Biologia não se completa apenas por meio da descrição da estrutura e função exercida pelas moléculas. Porém, muitas vezes, o que deve ser considerado são os processos de desenvolvimento (ontogenéticos ou filogenéticos) e as relações ecológicas e evolutivas que os seres vivos mantêm entre si e seu ambiente, lembrando ainda que em certas relações (e.g. parasitismo) o meio ambiente em que o parasita vive é o próprio organismo que o hospeda.

Diversos temas e consequências que influenciam os modos de se definir o conceito vida emergem a partir da filosofia da Microbiologia. No entanto, como previamente anunciado, consideraremos apenas consequências relacionadas ao conceito vida formulado por Bedau. Desta maneira, o conceito vida se aplica a populações ou níveis hierárquicos superiores e não a indivíduos. Estes, por serem incapazes de evoluir, não satisfazem o critério de adaptação flexível. Além disso, ao distinguir entre vida primária e vida secundária, o autor admite a existência de uma concepção hierárquica sobre os sistemas vivos. O exemplo da mula, citado anteriormente, é bastante ilustrativo, pois nos diversos conceitos vida que incluem a reprodução como um critério indispensável, a mula se torna uma anomalia. Nessa mesma categoria, incluem-se as hemácias e vírus. Hemácias metabolizam, mas não têm material genético; ao contrário, os vírus têm material genético, mas não metabolizam. Desse modo, se entre os critérios de definição do conceito vida incluírem-se compulsoriamente metabolismo ou reprodução, elimina-se uma das entidades ou outra. Essas entidades biológicas podem, todavia, ser consideradas formas secundárias de vida, caso se admita a concepção hierárquica. Finalmente, organismos não vivem isoladamente ou em oposição ao ambiente circundante; mas, para viver, têm de trocar informações entre si e o ambiente. Neste caso, não se pode pensar sobre um ser vivo desconsiderando as suas interações com outros viventes e com o ambiente onde habitam.

A filosofia da Microbiologia pode fundamentar a proposta de Bedau e os exemplos extraídos do mundo microbiológico podem ser utilizados com proveito em sala de aula. Os estudos realizados sobre microbiologia mostram que, no decorrer da evolução, os micro-organismos mantiveram relações intra e interespecíficas íntimas. A abordagem de tais relações constitui um problema se os organismos em si próprios forem considerados entidades individuais nitidamente definidas no tempo e espaço. Adicionalmente, impõe obstáculos que dificultam aceitar a competição como importante mecanismo seletivo e universal, ambos no darwinismo e na teoria sintética da evolução (DUPRÉ; O’MALLEY, 2009). No entanto, como vimos, as relações cooperativas são tão ou mais importantes para implementar evolução. Ao invés de sempre haver conflitos de interesses entre organismos, o que observamos é a existência de uma variedade de interações mutualistas, o que exige uma compreensão relacional e hierárquica da vida; sobretudo porque vida ocorre em diversos graus e níveis. Finalmente, dos pontos de vista ontológico e epistemológico, o conceito biológico vida situa-se nas zonas internalista e relacional. Quanto à última, as evidências advindas da filosofia da Microbiologia contribuem 
para sua a ampliação e explicitação, o que é importante para compreender melhor fenômenos ecológicos e evolutivos.

Um ensino em Biologia que recorra a um conceito de vida e seus fundamentos terá condições de integrar conceitos, modelos, analogias e metáforas em torno de um eixo unificador. Desse modo, temas aparentemente diversos e dispersos poderiam ser unificados, o que facilitaria bastante o aprendizado sobre o fato de que conceitos não são entidades abstratas estanques, mas têm um dinamismo cambiante que resulta da interação entre eles.

\section{CONSIDERAC̣̃̃ES FINAIS}

Articulamos o modelo de perfil conceitual, as pesquisas sobre o perfil conceitual de vida e elaborações provindas da filosofia da Microbiologia com o propósito de estabelecer um referencial para o processo de ensino/aprendizagem em Biologia. Mantivemos a perspectiva de que um ensino de Biologia mais sintético e menos analítico pode ser obtido se os exemplos utilizados e a explicitação das zonas que compõem o perfil conceitual forem considerados. Nossa hipótese é a de que o que foi aqui enunciado poderá contribuir para um ensino de Biologia menos enciclopédico e mais próximo da Biologia atual.

No entanto, é inevitável que surjam questionamentos sobre a proposta aqui elaborada: como construir modelos de ensino úteis para o aprendizado em sala de aula da educação básica e licenciatura em Biologia? Que tipos de materiais didáticos poderiam ser construídos a partir da perspectiva apresentada? Há outras consequências que poderiam ser extraídas a partir da filosofia da Microbiologia? Qual seria o impacto da utilização dessa proposta sobre a aprendizagem efetiva? De que maneira os professores encarariam a utilização da proposta em seu cotidiano? Haveria outros conceitos sobre vida que poderiam ser integrados à zona relacional do conceito biológico vida?

Ao elegermos a filosofia da Microbiologia como lugar de reflexão, esperamos também estar contribuindo para que essa ciência seja valorizada no contexto educacional. Assim, podemos também perguntar: qual seria a concepção sobre micro-organismos e suas interações, mantida por professores e alunos? De que forma o tema é discutido em sala de aula e em livros didáticos? O conceito de micro-organismo exibe um perfil conceitual? Quais seriam as relações entre a história da constituição da microbiologia e o tratamento que é dado ao assunto na mídia, na escola e nos livros didáticos? O que poderia ser feito para que houvesse uma inserção mais ampla do tema no ensino em Biologia?

Esperamos, ainda, ter contribuído para reforçar o programa de pesquisa sobre perfis conceituais. A utilização do modelo perfil conceitual faz com que a complexidade dos conceitos e teorias da ciência contemporânea possam ser analisadas e melhor compreendidas. Além disso, permite explicitar quais seriam as noções cotidianas que temos sobre um conceito científico. Enfim, a aplicação do 
modelo pode também facilitar o agrupamento de um conjunto de pesquisas científicas aparentemente desconectadas e extrair dele consequências filosóficas sobre a concepção relacional do conceito vida. A adesão ao programa de pesquisas sobre a aplicação do modelo perfil conceitual, aliado à filosofia da ciência, metafísica e ontologia, mostra-se, portanto, promissora para explicitar os fundamentos ontológicos e epistemológicos de teorias científicas.

\section{REFERÊNCIAS BIBLIOGRÁFICAS}

AUSUBEL, D.; NOVAK, J.; HANESIAN, H. Psicologia Educacional. Rio de Janeiro: Interamericana, 1980.

ARAVIND, L.; ANANTHARAMAN, V.; LYER, L. M. Evolutionary connections between bacterial and eukaryotic signaling systems: a genomic perspective. Current Opinion in Microbiology, [s.1], v. 6, p. 490-497, 2003.

BACHELARD, G. A filosofia do não. São Paulo: Abril Cultural (Col. Os Pensadores), 1978.

BEDAU, M. The nature of life. In: BODEN, M. The philosophy of artificial life. Oxford: Oxford University Press, pp. 332-357, 1996.

BEDAU, M. Four puzzles about life. Artificial Life, [s.1], 4(2), p.125-140, 1998.

BRASIL,Ministério da Educação e Cultura. Orientações curriculares para o ensino médio - ciências da natureza, matemática e suas tecnologias. Brasília: MEC, 2006.

COUTINHO, F. A. Construção de um perfil conceitual de vida. 2005. Tese (Doutorado em Educação) Faculdade de Educação, Universidade Federal de Minas Gerais, 2005.

COUTINHO, F. A.; MORTIMER E. F.; EL-HANI, C. N. Construção de um perfil para o conceito biológico de vida. Investigações em Ensino de Ciências, v.12(1), p. 115-137, 2007.

DAVEY, M. E.; O’TOOLE, G. A. Microbial Biofilms: from ecology to molecular genetics. Microbiology and Molecular Biology Reviews, [s.1], 64: 847-867, 2000.

DUPRÉ, J.; O'MALLEY, M. A. Varieties of living things: life at the intersection of lineage and metabolism. Philosophy and Theory in Biology, [s.1], v. 1; p. 003, 2009.

EMMECHE, C.; EL-HANI, C. N. Definindo Vida. In: EL-HANI, C. N. e VIDEIRA, A. A. P. (Orgs.). O que é vida? Para Entender a Biologia do Século XXI. Rio de Janeiro: Relume Dumará, 2000.

FENCHEL, T. Origin and early evolution of life. Oxford: Oxford University Press, 2002.

FEYERABEND, P. Against method. London: Verso, 1975.

HANSON, N. R. Patterns of discovery. Cambridge: Cambridge University Press, 1958.

KAFATOS, F. C.; EISNER, T. Unification in the century of biology. Science, [s.l], v.303, p. 1257, 2004.

KITCHER, P. The advancement of science. Oxford: Oxford University Press, 1993.

KUHN, T. The structure of scientific revolutions. Chicago: University of Chicago Press, 1970.

MAHNER, M. Operationalist Fallacies in Biology. Science \& Education, [s.1], v.7, p. 403-421, 1998.

MARGULIS, L. O planeta simbiótico. Rio de Janeiro: Rocco, 2001.

MARGULIS, L. Do kefir à morte. In: BROCKMAN, J. e MATSON, K. As coisas são assim. São Paulo: Cia das Letras, 2002.

MORAN, N. A.; BAUMANN, P. Bacterial endosymbionts in animals. Current Opinion in Microbiology, [s.1], 3, p. 270-275, 2000.

MORAN, N.A.; JARVIK, T. Lateral transfer of genes from Fungi underlies carotenoid production in aphids. Science. [s.1], v.328, p. 624-627, 2010.

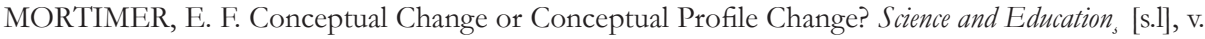
4, p. 267-285, 1995.

MORTIMER, E. F. Linguagem e formação de conceitos no ensino de ciências. Belo Horizonte: Ed. UFMG, 2000.

O’MALLEY, M. A.; DUPRÉ, J. Towards a philosophy of microbiology. Studies in History and Philosophy of Biological and Biomedical Sciences, [s.1], v. 38, p. 775-779, 2007a. 
O’MALLEY, M. A.; DUPRÉ, J. Size doesn't matter: towards a more inclusive philosophy of biology. Biology and Philosophy, [s.l], 22, p. 155-191, 2007b.

O’TOOLE, G.; KAPLAN, H. B.; KOLTER, R. Biofilm formation as microbial development. Annual Review of Microbiology, 54, p. 49-79, 2000.

REANNEY D.C., ROBERTS W.P. AND KELLY W.J. Genetic interactions among microbial communities. In: BULL A.T. AND SLATER J.H. (Eds), Microbial Interactions and Communities, London, UK: Academic. Press, 1982. pp. 287-322.

SAGAN, L.M. On the origin of mitosing cells. Journal of Theoretical Biology, [s.l], v.14, p. 225-274, 1967. TIMMIS, N. J. et. al. Endosymbiotic gene transfer: organelle genomes forge eukaryotic chromossomes. Nature Reviews Genetics, [s.1], v.5, p. 123-135. 2004.

VIDEIRA, A. A. P. Para que servem as definições? In: EL-HANI, C. N. e VIDEIRA, A. A. P. (Orgs.). O que é vida? Para Entender a Biologia do Século XXI. Rio de Janeiro: Relume Dumará, 2000.

WERTSCH, J.V. Vygotsky and the social formation of mind. Cambridge, MA: Havard University Press. 1985. ZHURAVLEV, Y. N.; AVETISOV, V. A. The definition of life in the context of its origin. Biogeoscience, [s.l] v. 3: 281-291, 2006.

Agradecimentos. Os autores são gratos a Marcos Soares Barbeiros pela tradução do resumo e aos dois revisores anônimos pelas contribuições para o aperfeiçoamento do trabalho 